\title{
Consórcio capim-braquiária e soja, produtividade das culturas e características qualitativas das silagens
}

\author{
Fernando de Paula Leonel ${ }^{1}$, José Carlos Pereira ${ }^{2}$, Marcone Geraldo Costa ${ }^{1}$, Paulo De Marco \\ Júnior $^{3}$, Luciano Aurélio Lara ${ }^{4}$, Daniel de Paula Sousa ${ }^{1}$, Cássio José da Silva ${ }^{1}$
}

\author{
${ }_{1}$ Programa de Pós-graduação em Zootecnia - Departamento de Zootecnia/UFV. \\ 2 Departamento de Zootecnia/UFV. \\ ${ }^{3}$ Laboratório de Ecologia Teórica e Síntese/DBG/ICB//UFG. \\ ${ }^{4}$ Consultor em Agropecuária.
}

RESUMO - Objetivou-se avaliar o cultivo de capim-braquiária e soja em consórcio ou exclusivamente. Avaliaram-se a produção de matéria seca (MS) e os teores de proteína bruta (PB) e nutrientes digestíveis totais (NDT) por hectare; os teores de proteína bruta, fibra em detergente neutro (FDN), lignina (LIG), carboidratos não-fibrosos (CNF), NDT, ácido butírico e ácido lático; o nitrogênio amoniacal; o teor de MS e o pH das silagens dessas culturas colhidas em dois estádios fenológicos $\left(R_{6}\right.$ e $\left.R_{7}\right)$ das plantas de soja. Na maioria das variáveis avaliadas, constatou-se viabilidade de ensilagem das culturas. A produção de MS foi maior no capim-braquiária em cultivo exclusivo, independentemente do estádio vegetativo. O teor de MS das silagens de capim-braquiária produzido em cultivo exclusivo foi baixo nos dois estádios vegetativos (19,55 e 19,49\%). Nas silagens oriundas do consórcio capim-braquiária e soja e de soja em cultivo exclusivo, o teor de MS foi mais elevado no estádio vegetativo $\mathrm{R}_{7}$. Independentemente do estádio, a soja em cultivo exclusivo produziu maiores teores de PB, CNF, LIG, NDT e maior quantidade de $\mathrm{PB}$, seguida pelo consórcio capim-braquiária e soja e pelo capim-braquiária em cultivo exclusivo, que comportaram de forma inversa quanto ao teor de FDN. A quantidade de NDT obtida no consórcio capim-braquiária e soja e no cultivo exclusivo de soja aumentou do estádio vegetativo $R_{6}$ para o $R_{7}$, enquanto, no capim-braquiária em cultivo exclusivo, diminuiu com avanço da maturidade das culturas. Em todas as silagens colhidas nos dois estádios vegetativos, os valores de $\mathrm{pH}$ e ácido butírico foram elevados e os valores de ácido lático foram baixos. No estádio $\mathrm{R}_{7}$, o teor de nitrogênio amoniacal das silagens foi menor que no $\mathrm{R}_{6}$. A utilização de soja cultivada em consórcio com capim-braquiária para produção de silagens é viável. Recomenda-se a colheita das culturas no estádio $\mathrm{R}_{7}$ das plantas de soja.

Palavras-chave: conservação de forragem, fermentação, interação agricultura e pecuária, recuperação de pastagens degradadas

\section{Intercropping of signal grass and soybean: productive performance of the crops and nutritional characteristics and quality of silage}

\begin{abstract}
The objective was to evaluate the culture of signal grass and soybean intercropping or in single cultures on the production of dry matter (DM) and crude protein (CP) and total digestible nutrients (TDN) per ha. It was evaluate, also, contents of CP, neutral detergent fiber (NDF), lignin (LIG), non-fibrous carbohydrates (NFC), NDT, butyric acid and lactic acid, ammonia nitrogen, the content of $\mathrm{DM}$ and $\mathrm{pH}$ of these silage cultures harvested in two phenological stages $\left(\mathrm{R}_{6}\right.$ and $\left.\mathrm{R}_{7}\right)$ of the soybean plants. The production of DM was greater in signal grass in single culture, regardless of the vegetative stage. The DM content of signal grass silage in single culture was low in both vegetative stages (19.55 and 19.49\%). In silages from signal grass and soybean intercropping and soybean in single culture, the content of DM was higher in the $\mathrm{R}_{7}$ vegetative stage. Regardless of the vegetative stage, soybean in single culture produced higher content of CP, NFC, LIG, TDN and higher amount of CP, followed by signal grass and soybean intercropping and signal grass in single culture, which showed inverse behavior for NDF content. The amount of TDN obtained in signal grass and soybean intercropping and soybean in single culture increased from the $R_{6}$ to $R_{7}$ vegetative stage, whereas in signal grass in single culture, decreased with advancing of the crop maturities. In all silages, harvested in the two vegetation stages, the values of $\mathrm{pH}$ and butyric acid were high and the values of lactic acid were low. In the $R_{7}$ stage, ammonia nitrogen level of the silages was lower than the $R_{6}$. It is feasible to use the signal grass and soybean intercropping for silage production, being recommended to harvesting the crops in R7 vegetative stage of the soybean plants.
\end{abstract}

Key Words: fodder conservation, fermentation, interaction agriculture and livestock, recovery of degraded pastures 


\section{Introdução}

A menor produção e o valor nutritivo das forragens no período seco têm merecido estudos visando proposição e validação de alternativas alimentares nessa época do ano. Uma das alternativas para solucionar o problema pode ser a produção de silagem, que pode ser conservada para suplementação da dieta dos animais durante o período de escassez de forragem (Ferreira 2001).

Entre as culturas com potencial para ensilagem, a soja, tanto na forma exclusiva como em associação a gramíneas, tem sido utilizada principalmente em virtude de sua capacidade de aumentar o teor de proteína do material ensilado (Evangelista, 1991; Obeid et al., 1992a,b). De acordo com Evangelista et al. (2003), quando colhida no início de enchimento de grãos (estádio $\mathrm{R}_{5}$ ), a soja pode apresentar, em média, 18 a $20 \%$ de proteína na matéria seca. Alguns autores afirmam que a adição de 40 a $50 \%$ de soja ao milho aumenta o teor de PB da silagem em 45 a 50\% (Eichelberger et al., 1997).

Há sugestões de que plantas de soja em cultivo exclusivo atingem o ponto ideal para corte e ensilagem no estádio fenológico $\mathrm{R}_{5}$, entretanto, resultados indicam que o ponto ótimo para ensilagem dessa leguminosa é o estádio $\mathrm{R}_{7}$ (Hintz et al., 1992). A soja, no entanto, como a maioria das leguminosas, possui características que dificultam sua conservação na forma de silagem. Entre essas características, destacam-se a baixa concentração de matéria seca e os elevados teores de proteína e matéria mineral, que promovem aumento da concentração de amônia e da capacidade tamponante e reduzem as concentrações de carboidratos solúveis.

Assim, objetivou-se com este trabalho avaliar a produção de MS e de alguns nutrientes por área e estudar as características qualitativas de silagens de soja, capimbraquiária e do material resultante do cultivo dessas duas culturas em consórcio colhidas em diferentes estádios de maturação.

\section{Material e Métodos}

O experimento foi conduzido na Fazenda Barra Mansa, localizada no município de Rio Casca, Zona da Mata de Minas Gerais. A calagem e adubação de plantio foram realizadas de maneira uniforme na área, conforme resultados da análise química do solo (Tabela 1), segundo as recomendações básicas para a cultura de soja.

A semeadura foi realizada em 1/12/2003, em área de pastagem degradada, com a finalidade de recuperação da fertilidade do solo e da produtividade de forragem na área. As culturas foram estabelecidas pelo método de plantio direto sobre palhada do pasto existente, após levantamento prévio das plantas daninhas infestantes e da adequada dessecação com herbicida sistêmico (glyphosate + 2,4-D) para o plantio direto.

A variedade de soja utilizada foi Pioneer DM 339 e o capim foi Brachiaria brizantha, cv. Marandu. A adu bação e o manejo das culturas foram realizados considerando cultura de soja em cultivo exclusivo, conforme recomendações para o uso de corretivos e fertilizantes em Minas Gerais: 5a aproximação, Viçosa, Minas Gerais.

Utilizaram-se três diferentes áreas da propriedade, porém com características edáficas semelhantes, distribuídas da seguinte forma: BCE - capim-braquiária em cultivo exclusivo (4,6 ha); BS - capim-braquiária em consórcio com soja (4,3 ha); SCE - soja em cultivo exclusivo (5,2 ha). Das três áreas, foram retiradas aleatoriamente amostras das culturas quando as plantas de soja das áreas com soja (BS e SCE) encontravam-se nos estádios fisiológicos $\mathrm{R}_{6}$ (pleno enchimento das vargens) e $\mathrm{R}_{7}$ (início da maturação dos grãos e $50 \%$ da folhas amareladas), de acordo com classificação de Fehr \& Caviness (1977).

O delineamento foi o inteiramente casualizado, com três áreas de cultivo com parcelas (estádios fisiológicos $\mathrm{R}_{6}$ e $\mathrm{R}_{7}$ ) repetidas no tempo. As amostragens nas três áreas (tratamentos) foram realizadas em triplicatas em cada uma das duas subparcelas (estádios), totalizando 18 repetições.

Tabela 1 - Resultados da análise química do solo

\begin{tabular}{cccccccr}
\hline $\mathrm{pH}$ & $\mathrm{MO}$ & $\mathrm{P}$ & & $\mathrm{K}$ & $\mathrm{Ca}$ & $\mathrm{Mg}$ & $\mathrm{H}+\mathrm{Al}$ \\
\hline & $(\mathrm{dag} / \mathrm{kg})$ & & $\left(\mathrm{mg} / \mathrm{dm}^{3}\right)$ & & & $\left(\mathrm{cmol}_{\mathrm{c}} / \mathrm{dm}^{3}\right)$ & $\mathrm{CTC}$ \\
6,2 & 2,32 & 1,1 & & 40 & 2,3 & 0,7 & 2,97 \\
\hline
\end{tabular}


Efetuou-se a estimativa de produção de matéria seca das culturas utilizando dados coletados em amostras de $0,25 \mathrm{~m}^{2}(0,5 \mathrm{~m} \times 0,5 \mathrm{~m})$ com três repetições por tratamento, feitas aleatoriamente nas parcelas.

Para avaliar a produção e a qualidade fermentativa das silagens (efeitos de tratamentos e dos estádios fenológicos), os resultados foram submetidos à análise de variância (ANOVA) em um esquema de medidas repetidas no tempo. O modelo de ANOVA de medidas repetidas é considerado um dos mais poderosos - possibilita identificar efeitos significativos com menor tamanho amostral - para análise de dados, pois permite o controle das variações entre as unidades amostrais de forma semelhante ao que ocorre no teste de "t" pareado (Zar, 1999). A análise foi feita de acordo com seguinte modelo:

$$
Y_{i j}=\mu+a_{i}+b_{j}+a b_{i j}+e_{i j},
$$

em que $Y_{i j}=$ observação referente à produção da $i$-ésima área noj-ésimo estádio fisiológico; $\mu=$ constante inerente ao modelo; $\mathrm{a}_{\mathrm{i}}=$ efeito do $i$-ésimo tratamento, com $i$ variando de 1 a $3 ; \mathrm{b}_{\mathrm{j}}=$ efeito do j-ésimo estádio fisiológico, obtido pelas datas de coleta, com $j$ variando de 1 a $2 ; a_{\mathrm{ij}}=$ efeito da interação área $\times$ estádio fisiológico; $\mathrm{e}_{\mathrm{ij}}=$ erro aleatório associado à observação, suposto normal e independentemente distribuído com média $=0$ (zero) e variância $\sigma^{2}$, ou seja, $\mathrm{e}_{\mathrm{ij}} \sim \mathrm{N}\left(0 ;\right.$ ó $\left.^{2}\right)$. As médias foram comparadas pelo teste de Student-Newman-Keuls com o nível de $5 \%$ de probabilidade.

As amostras coletadas foram picadas em picadeira estacionária acoplada a tomada de potência do trator e as silagens foram preparadas utilizando-se baldes de polivinil carbono com capacidade para $5 \mathrm{~kg}$ de material fresco, nos quais foram adaptados flanges de silicone nas tampas para permitir o escoamento de gases. Após o enchimento, os baldes foram hermeticamente lacrados com fitas adesivas para evitar a troca de ar com o meio.

Determinaram-se os teores de matéria seca (MS), proteína bruta (PB), fibra em detergente neutro (FDN), extrato solúvel em tratamento com éter (EE), proteína insolúvel em detergente ácido (PIDA) e lignina, de acordo com metodologia descrita por Silva \& Queiroz (2002).

A abertura dos silos foi feita 60 dias após a ensilagem. Uma fração de amostra da silagem de cada tratamento foi prensada para extração do suco e posterior determinação do $\mathrm{pH}$, utilizando-se potenciômetro digital (Digimed); do nitrogênio amoniacal/nitrogênio total, $\left.\mathrm{N}-\mathrm{NH}_{3} / \mathrm{NT}\right) \times 100$, segundo normas da AOAC (1995); do teor de ácido butírico, por cromatografia gasosa; e do teor de ácido lático, por cromatografia líquida de alta performance (HPLC) utilizando-se coluna de troca catiônica (Polyspher
OA HY 51272; Merck, Amsterdam), de modo que a fase móvel consistiu de $\mathrm{H}_{2} \mathrm{SO}_{4}(0,004 \mathrm{~mol} / \mathrm{L})$ a uma taxa de $0,6 \mathrm{~mL} / \mathrm{min}$ a $40^{\circ} \mathrm{C}$.

Os nutrientes digestíveis totais (NDT) foram estimados de acordo a equação proposta por Weiss (1992) e adotada pelo NRC (2001):

$$
\mathrm{NDT}=\left[\mathrm{PBD}+(2,25 \times \mathrm{AGD})+\mathrm{FDN}_{\mathrm{cp}} \mathrm{D}+\mathrm{CNFD}\right]-7
$$

em que: $\mathrm{PBD}=\mathrm{PB} \times \mathrm{EXP}^{[-1,2 \times(\mathrm{PIDA} / \mathrm{PB})]} ; \mathrm{AGD}=\mathrm{EE}=$ matéria solúvel em éter de petróleo, se $E E<1 ; A G=0$; $\left.\mathrm{FDN}_{\mathrm{cp}} \mathrm{D}=\left[0,75 \times\left(\mathrm{FDN}_{\mathrm{cp}}-\mathrm{LIG}\right)\right] \times\left[1-\left(\mathrm{LIG}_{\mathrm{FDN}}\right)_{\mathrm{cp}}\right)^{0,667}\right]$, em que FDNcp $=$ FDN corrigida para cinzas e proteína; $\mathrm{CNFD}=0,98 \times\{100-[(\mathrm{FDN}-\mathrm{PIDN})+\mathrm{PB}+\mathrm{EE}+\mathrm{CINZA}\} \times \mathrm{PAF}$ adotando-se PAF (fator de ajuste ao processamento $)=1$.

\section{Resultados e Discussão}

Não houve interação áreas $\times$ estádios vegetativo das culturas para a produção de matéria seca por hectare (PMS/ha), que não foi influenciada pelo estádio vegetativo, mas apresentou diferenças entre as áreas de amostragem. $\mathrm{A}$ área com $\mathrm{BCE}$ foi superior $(\mathrm{P}<0,05)$ às demais nos dois estádios avaliados. As áreas com consórcio de BS e SCE não diferiram $(\mathrm{P}>0,05)$ entre os estádios fenológicos (Figura 1A).

Os valores de produtividade das silagens obtidos com $\mathrm{SCE}$ nos estádios $\mathrm{R}_{6}$ e $\mathrm{R}_{7}$ foram próximos aos descritos na literatura. Koivisto et al. (2003) realizaram estudos com silagens de dois cultivares de soja em duas idades ao corte e obtiveram produtividade de matéria seca de 5.910 a $7.950 \mathrm{~kg} / \mathrm{ha}$. Hoffman et al. (2004) verificaram, no estádio $\mathrm{R}_{7}$, produtividade de aproximadamente $4.000 \mathrm{~kg} / \mathrm{ha}$ de silagem de soja. Do mesmo modo, Blount et al. (2006) relataram produtividade de $5.673 ; 6.187 ; 7.963 ;$ e $6.870 \mathrm{~kg} / \mathrm{ha}$ de silagens de soja na forragem colhida, respectivamente, com 103; 110; 117 e 124 dias de idade. Jiménez et al. (2004), no entanto, obtiveram produtividade média de apenas $3.500 \mathrm{~kg}$ de MS/ha em silagens de soja.

Houve interação estádio fenológico $\times$ área para o teor de proteína bruta (PB) na MS das silagens, que, nas silagens obtidas do BS e SCE, foi maior $(\mathrm{P}<0,05)$ no estádio $\mathrm{R}_{7}$ em comparação ao $\mathrm{R}_{6}$ (Figura $1 \mathrm{~B}$ ).

Nas silagens obtidas com SCE, os teores PB, de 18,55 e 20,51\% (Figura 1B), foram próximos aos de 18,5 e 19,5\% de PB, determinados por Hoffman et al. (2004) em silagens de soja nos estádios $\mathrm{R}_{6}$ e $\mathrm{R}_{7}$, respectivamente. Em pesquisa realizada por Blount et al. (2006), silagens de soja feitas aos 110 e 117 dias após a emergência da cultura tiveram 
médias de 20,8 e 20,9\% de PB, todavia, em trabalho de Coffey et al. (1995), foram encontradas médias de 16,0 a 20,6\% de $P B$ na MS de silagens feitas nos estádios $R_{2}, R_{4}$ e $R_{6}$ em dois anos consecutivos. O NRC (2001) cita $17,4 \%$ de PB para silagens de soja, valor médio obtido de 20 trabalhos.

Os teores de 5,07 e 5,17\% de PB obtidos nas silagens de BCE confeccionadas quando as plantas de soja encontravam-se nos estádios $\mathrm{R}_{6}$ e $\mathrm{R}_{7}$, in casu, aos 117 e 124 dias pós-plantio, foram semelhantes aos encontrados por Evangelista et al. (2004) em silagens de Brachiaria brizantha (média de 5,7\% de PB). Nas silagens obtidas do consórcio de capim-braquiária e soja, obtiveram-se teores de PB intermediários, o que era previsível para a mistura de forrageiras dessa natureza, em virtude da diluição de massas, pois os teores de PB da massa forrageira da SCE são mais elevados que os da massa forrageira de BCE.

$\mathrm{Na}$ tentativa de elevar o teor de PB da massa ensilada, Obeid et al. (1992a) testaram vários consórcios e arranjos de semeadura entre milho e leguminosas e obtiveram com milho em cultivo exclusivo silagens com $5,2 \%$ de $\mathrm{PB}$, ao passo que nos consórcios, 5,9\% de PB no milho estabelecido com soja em um arranjo de 6 plantas de milho e 25 plantas de soja por metro linear e, 6,8\% PB no arranjo 6 plantas de milho e 50 plantas de soja por metro linear. Obeid et al. (1992b), no entanto, testaram silagens de milho em cultivo exclusivo com 5,33\% de PB e silagens de milho em cultivo com soja, em um arranjo de 6 plantas de milho e 20 plantas de soja por metro linear, com 7,79\% de PB. Carneiro \& Rodrigues (1980), também nessa linha de pesquisa, obtiveram silagens de milho com $8,4 \%$ de PB e silagens de milho e soja, em uma proporção de massa 60:40, com $13,78 \%$ de PB na MS. Ressalta-se que a proporção de massa das forragens do BS foi de 50,23:49,77, ou seja, próxima a 1:1. Evangelista et al. (2003) obtiveram silagens com as seguintes relações massa soja:milho e teores de proteína: 0:100 - 7\% de PB; 15:85 - 8\% de PB; 30:70 - 11\% de PB; 45:55 - 12\% de PB; 40:60 - 13\% de PB; 75:25 - 14\% de PB; 90:10 - 16\% de PB; e 110:0 - 18\% de PB.

Houve interação área $\times$ estádio fenológico para produção de proteína bruta por hectare. Independentemente do estádio vegetativo, a SCE apresentou a maior produção de $\mathrm{PB} /$ ha, seguida do consórcio, que resultou em produção de $\mathrm{PB} /$ ha maior que a obtida no BCE (Figura 1C).

Poucos trabalhos têm sido realizados para avaliação da produtividade de proteína no consórcio capimbraquiária e soja, todavia, Blount et al. (2006) registraram valores de PB de $1.101 ; 1.286 ; 1.662$; e 1.4650 kg/ha em silagens de soja em cultivo exclusivo produzidas, respectivamente, com plantas de 103; 110; 117 e 124 dias de idade. Hoffman et al. (2004) também relataram produção de PB de
730 a $750 \mathrm{~kg} / \mathrm{ha}$ em silagens de soja confeccionadas nos estádios $\mathrm{R}_{6}$ e $\mathrm{R}_{7}$.

A produção de $\mathrm{PB}$ de $1.106 \mathrm{~kg} / \mathrm{ha}$ obtida na silagem de SCE no estádio $\mathrm{R}_{6}$ foi semelhante aos dados descritos por Koivisto et al. (2003), de 770 a $1.050 \mathrm{~kg} / \mathrm{ha}$ para silagens de soja de diversos cultivares.

Lempp et al. (2000) relataram produtividade média de $720 \mathrm{~kg} / \mathrm{ha}$ de PB para silagens de plantas de soja e milho cultivadas em arranjos de uma ou duas linhas de soja nas entrelinhas de milho. Também em consórcio de soja e milho, Obeid et al. (1992a) observaram produções de PB de 576,5 e $649,6 \mathrm{~kg} / \mathrm{ha}$, resultantes de cultivos em arranjos de semeadura: 6 plantas de milho e 25 plantas de soja e 6 plantas de milho e 50 plantas de soja por metro linear, respectivamente. No consórcio soja e sorgo, Silva et al. (2003) avaliaram quatro cultivares de cada uma dessas culturas, com destino à ensilagem, e relataram $1.448 \mathrm{~kg}$ de $\mathrm{PB} / \mathrm{ha}$, como média da produtividade dos diferentes arranjos e repetições. Entretanto, a produção média de MS dos consórcios dessas culturas foi de $14.193 \mathrm{~kg} / \mathrm{ha}$, valor bem acima dos encontrados nesta pesquisa para o consórcio soja e capim-braquiária. Rezende et al. (2000) também avaliaram o consórcio soja e sorgo para silagem e registraram produção média de $1.683 \mathrm{~kg} / \mathrm{ha}$ de $\mathrm{PB}$, porém, com produtividade média de 13.190 de MS/ha.

Não houve interação de áreas de cultivo $\times$ estádios fenológicos das culturas para o teor de fibra em detergente neutro (FDN) na MS das silagens. O estádio vegetativo também não afetou essa variável, que apresentou diferenças entre as áreas de cultivo. Nos dois estádios fenológicos avaliados, os teores médios de FDN das silagens de BCE foram superiores $(\mathrm{P}<0,05)$ aos das silagens obtidas do BS, que, por sua vez, foram superiores $(\mathrm{P}<0,05)$ aos das silagens de SCE (Figura 1D).

A maior concentração de FDN na MS de gramíneas em comparação a de leguminosas é normal e, como a relação de massa do BS se aproximou de 1:1 em plantas de capimbraquiária e soja, justifica-se o valor intermediário de FDN em comparação aos obtidos no BCE e SCE.

Os resultados obtidos neste trabalho para o teor de FDN nas silagens de capim-braquiária, 49,16 e 48,95\%, foram próximos aos descritos por Mustafa \& McGill (2005) em silagens de soja, 44 e 49\% de FDN. Coffey et al. (1995) também observaram valores de 38,3 a 48,3\% de FDN em plantas de soja e Undersander et al (2006) relataram valor mínimo de $33 \%$, médio de $39 \%$ e máximo de $47,5 \%$. Em trabalho realizado por Blount et al. (2006), constatou-se redução linear, de acordo com a idade, no teor de FDN em silagens de soja. Esses autores observaram teor de 56,7\% de FDN aos 89 dias pós-emergência, que passou para 50,2\% 
A

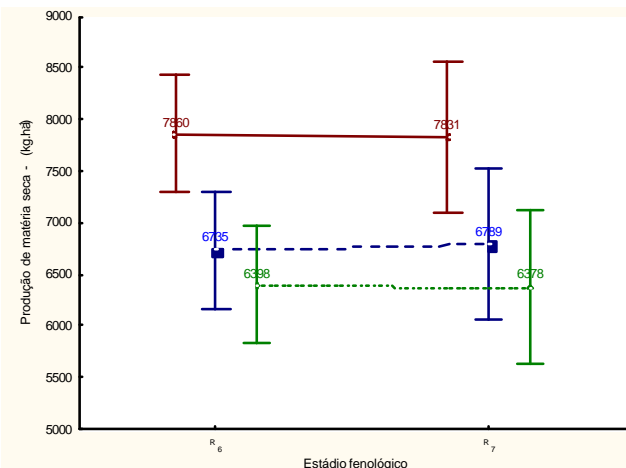

$\mathrm{C}$
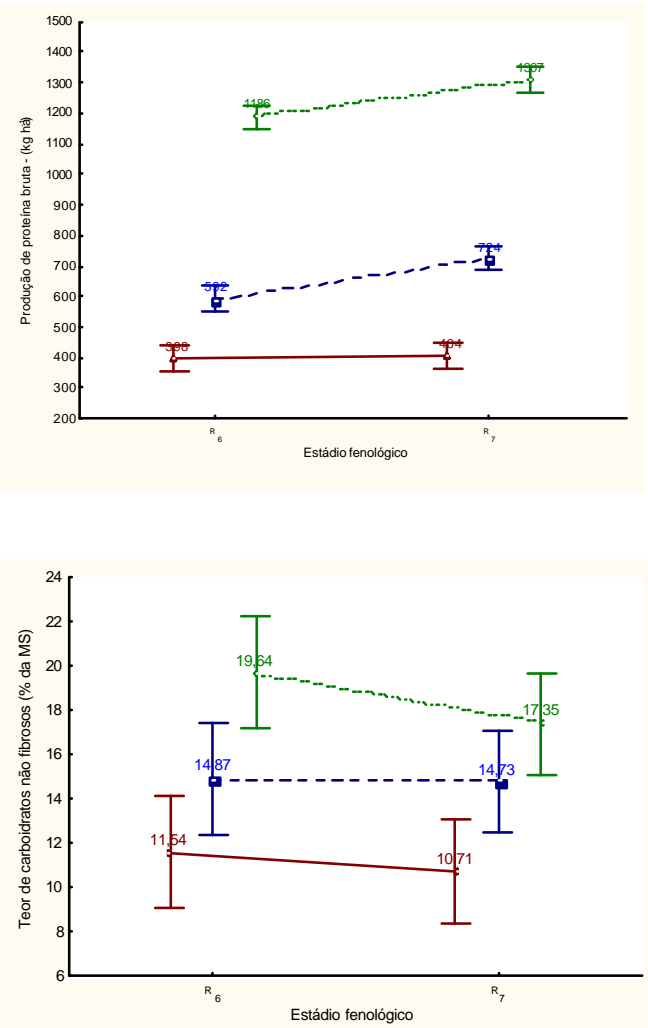

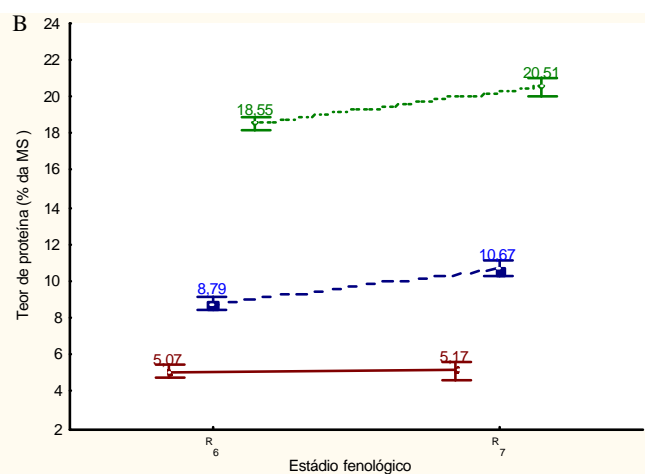

$\mathrm{D}$

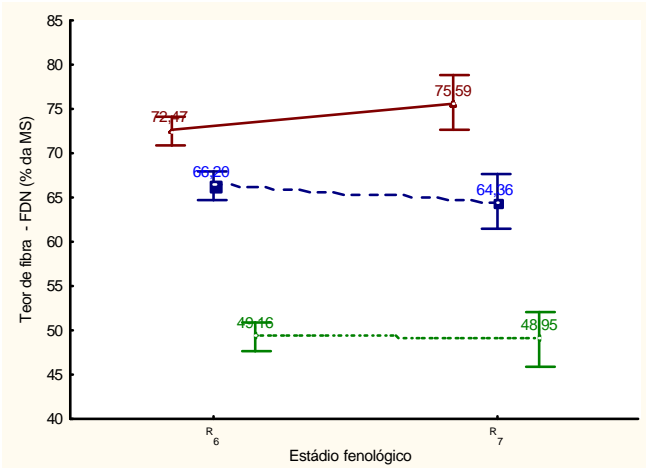

F

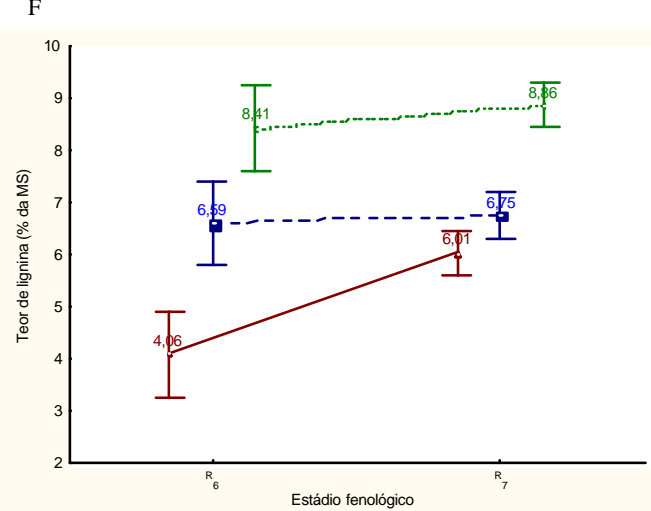

BCE = capim-braquiária em cultivo exclusivo.

BS = consórcio capim-braquiária e soja.

$\lessdot$ SCE = soja em cultivo exclusivo.

Figura 1 - Produção de matéria seca, teores de proteína bruta, produção de proteína bruta por hectare, fibra em detergente neutro, carboidratos não-fibrosos e lignina na MS das silagens.

As barras representam o intervalo de confiança de $95 \%$.

aos 103 dias e $43 \%$ aos 124 dias de idade, fato atribuído ao aumento de massa de grãos em relação à planta inteira com o avanço da idade.

As concentrações de 72,47 e 75,59\% de FDN na MS obtidas nas silagens do BCE estão de acordo com a maioria dos valores constantes na literatura para gramíneas forrageiras. Silva et al. (2005) encontraram em silagens de Brachiaria brizantha $75,91 \%$ de FDN, Chizotti et al. (2005), 74,28\%, e Evangelista et al. (2004), 67,65 a 69,39\% de FDN, em silagens de Brachiaria brizantha.
Não houve interação estádio fenológico das culturas $x$ áreas de cultivo para o teor de carboidratos não-fibrosos (CNF) das silagens, que não foi afetado pelo estádio fenológico das plantas, mas diferiu entre as áreas de cultivo. Nos dois estádios avaliados, as silagens de SCE apresentaram maior $(\mathrm{P}<0,05)$ teor de $\mathrm{CNF}$, seguidas pelas silagens resultantes do $\mathrm{BS}$ que, por sua vez, foram superiores $(\mathrm{P}<0,05)$ às obtidas com $\mathrm{BCE}$ (Figura $1 \mathrm{E})$. A concentração de CNF nas silagens de BCE não variou entre os dois estádios fenológicos avaliadas, fato relacionado à proximi- 
dade entre as avaliações (sete dias). Chizzotti et al. (2005) avaliaram silagens de Brachiaria brizantha e encontraram teor médio de CNF de 11,04\%. A ligeira queda no teor de CNF nas silagens de $\mathrm{SCE}$ no estádio $\mathrm{R}_{7}$, em comparação à do $\mathrm{R}_{6}$, deve-se ao aumento dos teores de PB e lipídeos com o avanço da idade das plantas de soja. O comportamento intermediário das silagens do BS está relacionado à diluição de massas entre as plantas de soja e do capim-braquiária.

Houve interação estádios fenológicos $\times$ área de cultivo para o teor de lignina na MS. Nos dois estádios $\left(\mathrm{R}_{6} \mathrm{e} \mathrm{R}_{7}\right)$, a silagem de SCE foi superior à silagem obtida do consórcio $(\mathrm{P}<0,05)$ que, por sua vez, foi superior à de capim-braquiária em cultivo exclusivo (Figura 1F). A superioridade das leguminosas sobre as gramíneas, quanto à concentração de lignina, é relatada por diversos autores, entre eles, Van Soest (1994). Novamente, o comportamentointermediário das silagens obtidas do consórcio de capim-braquiária e soja é atribuído à diluição de massas.

Os teores de 8,41 e 8,86\% de lignina na MS encontrados nas silagens de soja em cultivo exclusivo nos estádios $R_{6}$ e $\mathrm{R}_{7}$ foram superiores, mas próximos, aos reportados por Mustafa \& McGill (2005), que observaram valores de 6,4 e $8,1 \%$ de lignina na MS de silagens de soja, enquanto Coffey et al. (1995) encontraram teores de 6 a 7,4\%.

Silva et al. (2005), em pesquisa com Brachiaria Brizantha ensilada, encontraram 5,12\% de lignina, valor compreendido no intervalo de 4,06 a $6,01 \%$ para BCE (Figura 1F).

Não foi constatada interação áreas de cultivo $\times$ estádio s fenológicos para o teor de MS das forrageiras no momento da ensilagem. Apenas o estádio vegetativo influenciou essa variável de forma significativa, uma vez que as silagens oriundas da soja em cultivo exclusivo e do consórcio de capim-braquiária e soja no estádio $R_{7}$ apresentaram maiores médias $(\mathrm{P}<0,05)$ de MS (Figura 2A). No estádio $R_{6}$, não houve diferença $(P>0,05)$ entre as áreas de cultivo.

O teor de MS da planta para ensilagem está relacionado às condições de fermentação do material e aos níveis de perdas no sistema; ideal é obter teores de MS de 28 a $35 \%$ (McDonald et al., 1991). Os teores de MS das forragens do BS e da SCE no estádio $\mathrm{R}_{7}$ aproximaram-se dessa faixa (Figura 2A).

Koivisto et al. (2003) obtiveram silagens de soja com média de $20,2 \%$ a $22,4 \%$ de MS no estádio $\mathrm{R}_{6}$. Todavia, Hoffman et al. (2004) observaram 19\% de MS em silagens de soja, enquanto Blount et al. (2006) avaliaram silagens dessa leguminosa feitas com plantas aos 103, 110, 117 e 124 dias pós-emergência e obtiveram em média 26; 26; 27 e 29\% de MS, respectivamente. Neste estudo, as plantas de soja no estádio $\mathrm{R}_{6}$ estavam com 117 dias pós-plantio e 110 dias pós-emergência.

O aumento de $18,75 \%$ para $25,87 \%$ no teor de MS da forragem do BS e SCE do estádio $R_{6}$ para o $R_{7}$ deve-se, principalmente, à senecência das plantas de soja, pois a MS das forragens do BCE praticamente não variou nesse período. O teor de MS da forragem do BCE (19,55\%) foi próximo do relatado por Silva et al. (2005).

Houve interação estádio fenológico $\times$ área de cultivo para o teor de nutrientes digestíveis totais (NDT) na MS das silagens. O teor médio de NDT aumentou do estádio $\mathrm{R}_{6}$ para o $\mathrm{R}_{7}$ nas silagens resultantes do BS e $\mathrm{SCE}$, porém, nas silagens da BCE, o comportamento dessa variável foi inverso (Figura 2B).

O valor de 60,95\% de NDT obtido nas silagens de SCE no estádio $\mathrm{R}_{6}$ foi próximo à média de $59,9 \%$ de NDT na MS considerada pelo NRC (2001). Todavia, Carneiro et al. (1982) avaliaram o conteúdo de matéria seca digestível (MSD) em silagens com $40 \%$ de soja e $60 \%$ de milho e encontraram média de $66 \%$. A matéria seca digestível (MSD), assim como a matéria orgânica digestível (MOD), pode refletir o conteúdo energético dos alimentos. Evangelista et al. (1983) trabalharam com diversos arranjos de semeadura para consórcio milho e soja e obtiveram silagens com 52 e 55\% de MSD.

Os valores intermediários de estimativa do NDT das silagens do BS, em comparação ao BCE e à SCE em cultivo exclusivo, tanto no $\mathrm{R}_{6}$ quanto no $\mathrm{R}_{7}$, estão relacionados à diluição de massa (soja e capim-braquiária) nessas áreas de cultivo.

Não houve interação estádios fenológicos $\times$ áreas de cultivo para o $\mathrm{pH}$ das silagens. O estádio vegetativo, isolado, diferente da área de cultivo, não afetou essa variável. $\mathrm{O}$ pH das silagens de capim-braquiária em ambos os estádios fenológicos foi inferior $(\mathrm{P}<0,05)$ ao das silagens obtidas do consórcio e da soja em cultivo exclusivo, que não diferiram entre si $(\mathrm{P}>0,05)$ (Figura 2C).

Segundo Kung Jr. \& Shaver (2001), o pH típico de silagens de leguminosas com 30 a $40 \%$ de MS e de silagens de gramíneas perenes de clima temperado varia de 4,3 a 4,7. Leibensperger \& Pitt (1987) também observaram pH de 4,45 em silagens de leguminosas com 25\% de MS e 4,26 nas silagens de gramíneas de clima temperado com esse mesmo teor de MS. Rangrab et al. (2000) observaram pH de 4,57 a 4,81 em silagem de alfafa e Jiménez et al. (2004), em silagens de soja e milho com relação de massa 1:1, registraram $\mathrm{pH}$ de 4,25. Evangeslista et al. (2003) observaram pH de 4,8 em silagem de soja.

Neste trabalho, independentemente da área de cultivo e do estádio fenológico, os valores de $\mathrm{pH}$ foram superiores aos reportados na literatura (Figura 2C). 
A interação estádios fenológicos $\times$ área de cultivo para a variável $\mathrm{N}-\mathrm{NH}_{3} / \mathrm{NT}$ foi significativa. No estádio $\mathrm{R}_{6}$, as silagens produzidas com a forragem do BS apresentaram maior $(\mathrm{P}<0,05)$ média de $\mathrm{N}-\mathrm{NH}_{3} / \mathrm{NT}$, enquanto as demais não diferiram entre si $(\mathrm{P}>0,05)$.No estádio $\mathrm{R}_{7}$, a média dessa variável no $\mathrm{BCE}$ foi maior $(\mathrm{P}<0,05)$ que a encontrada nas $\mathrm{BS}$ e SCE, que não diferiram entre si (Figura 2D).

Kung Jr. \& Shaver (2001) consideram normais em silagens de leguminosas de clima temperado concentrações de $\mathrm{N}-\mathrm{NH}_{3} / \mathrm{NT}$ de 10 a $15 \%$ da MS e, em silagens de gramíneas perenes de clima temperado, 8 a $12 \%$. Neste estudo, no estádio $\mathrm{R}_{6}$, o teor médio de $\mathrm{N}-\mathrm{NH}_{3} / \mathrm{NT}$ nas silagens de todas as áreas de cultivo foi maior que o preconizado (Figura 2D), enquanto, no estádio $\mathrm{R}_{7}$, o teor de $\mathrm{N}-\mathrm{NH}_{3} / \mathrm{NT}$ nas silagens do consórcio $(10,48 \%)$ e da soja em cultivo exclusivo $(9,24 \%)$ manteve-se no intervalo desejado.

Evangelista et al. (1991b) avaliaram silagem de duas variedades de soja cultivadas em consórcio com milho em diversas densidades de semeadura e obtiveram valores de 11 a $12,7 \%$ de $\mathrm{N}-\mathrm{NH}_{3} / \mathrm{NT}$ na MS. Obeid et al. (1992a) estudaram consórcios de milho com várias leguminosas em diversas densidades de semeadura e não constataram diferenças nessa variável em 12 combinações. Esses autores obtiveram $6,3 \%$ de $\mathrm{N}-\mathrm{NH}_{3} / \mathrm{NT}$ na silagem de milho com soja (6:25 plantas por metro linear), $8,5 \%$ na silagem de milho com crotalária (6:20 plantas por metro linear) e $9,1 \%$ na silagem de milho com mucuna preta $(6: 12$ plantas por metro linear).

Broderick et al. (2001) trabalharam com silagens de outras leguminosas - alfafa, trevo-vermelho e mistura dessas duas - e obtiveram na MS dessas silagens 8,4; 9,8 e $8,0 \%$ de $\mathrm{N}-\mathrm{NH}_{3} / \mathrm{NT}$, respectivamente. Rangrab et al. (2000) avaliaram o efeito de inoculantes microbianos e enzimas sobre a conservação de silagens de alfafa e, na silagem controle, sem aditivo, obtiveram 11,03\% $\mathrm{N}-\mathrm{NH}_{3}$ /NT na MS.

Os teores de 20,70 e $14,39 \% \mathrm{~N}^{-\mathrm{NH}_{3}}$ /NT na MS das silagens de Brachiaria brizantha são inferiores aos $21,18 \%$ encontrados por Chizzotti et al. (2005) nessa mesma forrageira. Teores de 10 a $18 \%$ na MS de silagens de Brachiaria brizantha foram citados por Corrêa et al. (2001).

Não foi constatada interação, nem efeito, das áreas de cultivo e dos estádios fenológicos sobre o teor de ácido butírico (Figura 2E).

De acordo com Kung Jr. \& Shaver (2001), em geral, silagens de leguminosas submetidas a adequado processo fermentativo possuem na matéria seca teores de ácido butírico inferiores a $0,5 \%$ e silagens de gramíneas perenes, teores de 0,5 a $1,0 \%$.
Os resultados de ácido butírico (Figura 2E) nas silagens de SCE estão de acordo com os preconizados para silagens de leguminosas. Os das silagens do consórcio também são aceitáveis, tanto para silagens de leguminosas quanto para de gramíneas. Em consórcio milho e soja para ensilagem, Obeid et al. (1985) registraram teor médio de 0,19\% de ácido butírico na MS, enquanto na silagem de milho em cultivo exclusivo (52.889 plantas/ha), registraram $0,12 \%$ desse ácido orgânico.

Não houve interação estádio vegetativo $\times$ áreas de cultivo para o teor de ácido lático. Também não houve efeito individual do estádio vegetativo nem das áreas de cultivo sobre essa variável (Figura 2F). A concentração normal de ácido lático em silagens de leguminosas com teor de MS entre 30 e $40 \%$ varia de 7 a $8 \%$ e em silagens de gramíneas perenes, de 6 a 10\% (Kung Jr. \& Shaver 2001). Os teores de ácido lático das silagens neste estudo não atingiram esse nível (Figura 2F), mas os 3,41 e 3,11\% observados nas silagens de BCE foram próximos da média citada por Andrade \& Melotti (2004), de 1,05 a 5,31\% da MS. Essas concentrações foram semelhantes ainda às de 2,39 a 3,52\%, citadas por Ferrari Jr. \& Lavezzo (2001) para silagens dessa mesma forrageira. Rodrigues et al. (2005) avaliaram o efeito da adição de 0 a $15 \%$ de polpa cítrica sobre a qualidade da silagem de capim-elefante e obtiveram concentrações de ácido lático de 3,87 a 6,81\% da MS. Martin et al. (1983) avaliaram a adição de 30, 40 e 50\% de soja ao milho e obtiveram silagens com, respectivamente, 4,85; 5,00 e 5,10\% de ácido lático na MS. Também em silagens oriundas do consórcio milho e soja, Obeid et al. (1985) observaram concentrações de 1,90 até 2,52\% de ácido lático na MS.

$\mathrm{Na}$ avaliação da produção de nutrientes digestíveis totais por área (NDT/ha), constatou-se interação áreas de cultivo $\times$ estádios fenológicos das culturas. A produção de $\mathrm{NDT} /$ ha nas silagens de $\mathrm{BCE}$ no estádio $\mathrm{R}_{7}$ reduziu em comparação à obtida no estádio $\mathrm{R}_{6}$. Nas demais áreas de cultivo, a tendência nesses dois estádios fenológicos foi inversa (Figura 3).

Em poucos trabalhos, há relatos da produção de energia oriunda de silagem de soja por unidade área. Blount et al. (2006) obtiveram produções de 3.482; 3.725; 4.842; e 4.190 kg/ha de MODIV (matéria orgânica digestível estimada pelo método in vitro ) em silagens de soja produzidas, respectivamente, com plantas com 103; 110; 117 e 124 dias de idade. Uma vez que a MOD e a MSD são indicativos do conteúdo energético dos alimentos, apesar de suas grandezas diferentes, a estimativa de NDT foi próxima da estimativa da MOD em quantidade considerável de alimentos para ruminantes. Desse modo, os teores 
A

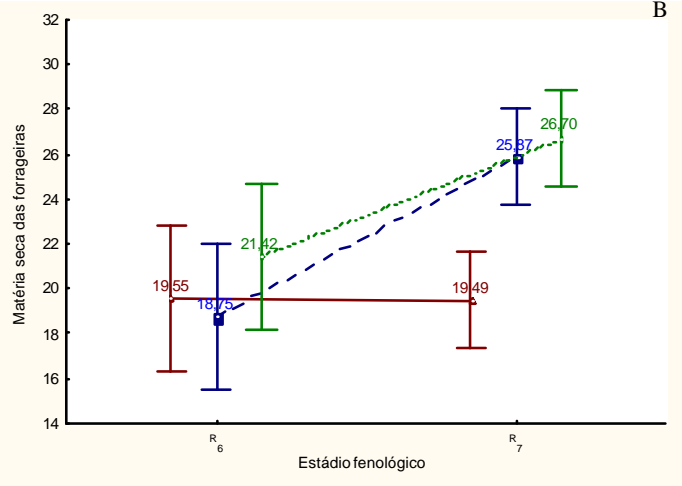

$\mathrm{C}$

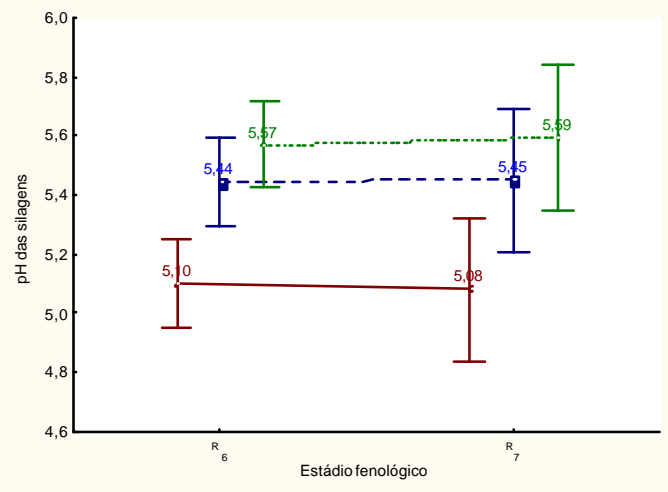

E

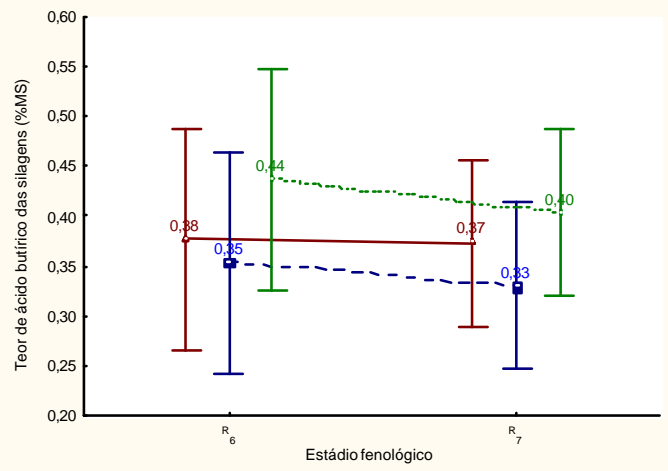

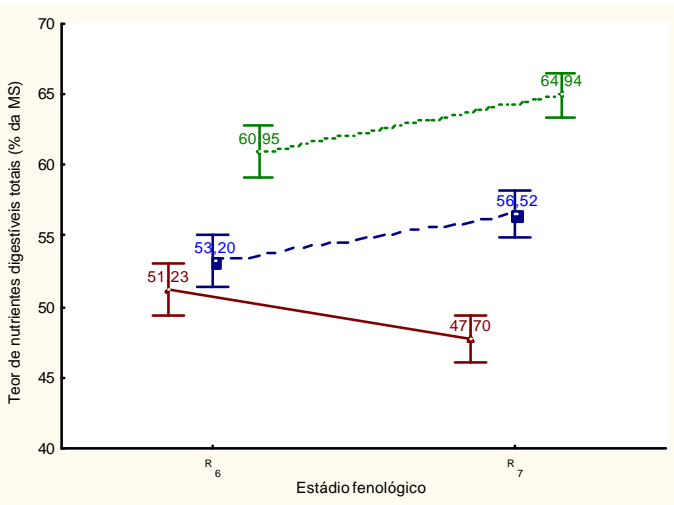

D

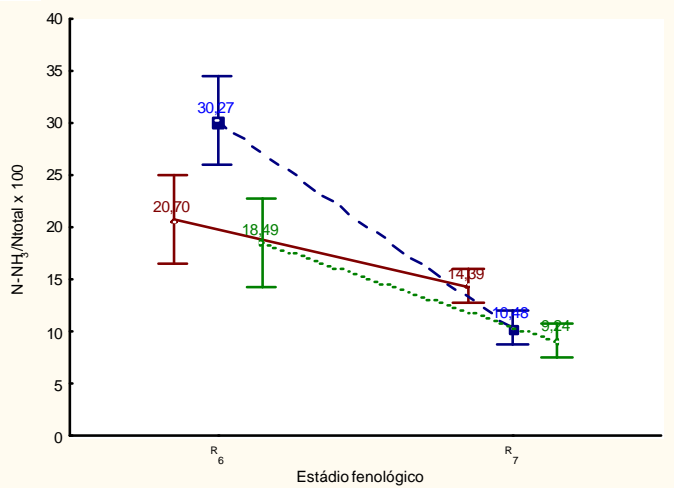

F

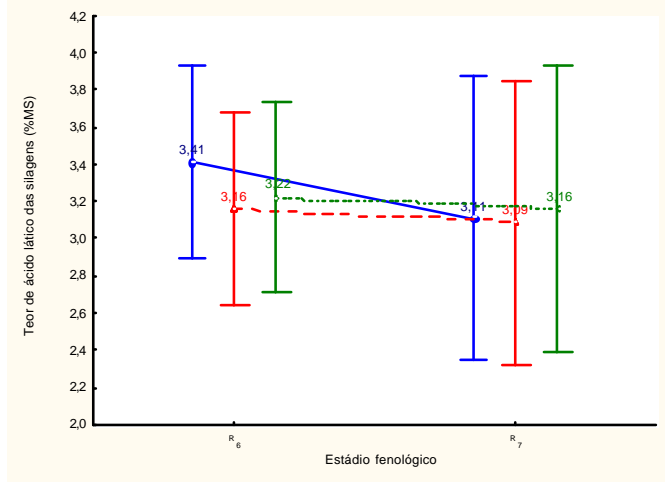

$\triangle \mathrm{BCE}=$ capim-braquiária em cultivo exclusivo.

BS = consórcio capim-braquiária e soja

$\diamond$ SCE = soja em cultivo exclusivo.

Figura 2 - Matéria seca, pH e teores de nutrientes digestíveis totais, nitrogênio amoniacal e ácidos butírico e lático na MS. As barras representam o intervalo de confiança de $95 \%$.

de NDT de 3.899 e $4.138 \mathrm{~kg} / \mathrm{ha}$ obtidos, respectivamente, com silagens de soja em cultivo exclusivo confeccionadas nos estádios $\mathrm{R}_{6}$ e $\mathrm{R}_{7}$, mantiveram-se no intervalo, do menor ao maior valor, relatado por Blount et al. (2006) para a produção de MOD por área.

\section{Conclusões}

É possível a utilização de soja cultivada em consórcio com capim-braquiária para produção de silagens. Recomenda-se a colheita das culturas no estádio $\mathrm{R}_{7}$ das plantas de soja. 


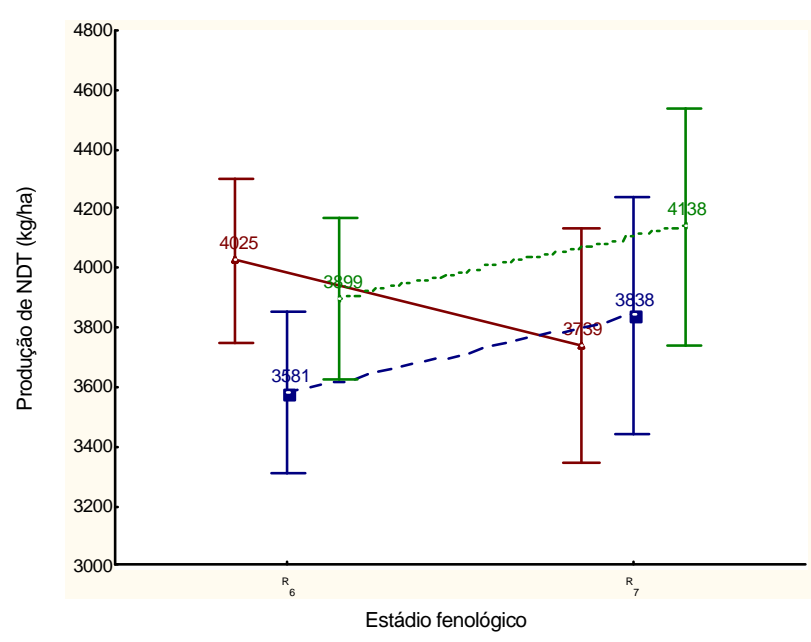

Figura 3 - Nutrientes digestíveis totais por área (NDT/ha) nas áreas de cultivos e nos estádios fenológicos das culturas.

BCE = capim-braquiária em cultivo exclusivo.

- BS = consórcio capim-braquiária e soja.

$\diamond$ SCE = soja em cultivo exclusivo.

As barras representam o intervalo de confiança de $95 \%$.

\section{Literatura Citada}

ANDRADE, S.J.T.; MELOTTI, L. Efeito de alguns tratamentos sobre a qualidade da silagem de capim-elefante cultivar Napier (Pennisetum purpureum, Schum). Brazilian Journal of Veterinary Research and Animal Science, v.41, n.6, p.409$415,2004$.

ASSOCIATION OF OFFICIAL ANALYTICAL CHEMISTS - AOAC. Official methods of analysis. 16.ed. Washington, D.C.: 1995. 1094 p.

BLOUNT, A.R.S.; WRIGHT, D.L.; SPRENKEL, R.K. et al. [2006]. Forage soybeans for grazing, hay and silage. Agronomy Department, Florida Cooperative Extension Service, Institute of Food and Agricultural Sciences, University of Florida. Revised July 2006. Disponível em: http: <http:// www.edis.ifas.ufl.edu> Acesso em: 18/1/2007.

BRODERICK, G.A.; WALGENBACH, R.P.; MAIGNAN, S. Production of lactating dairy cows fed alfalfa or red clover silage at equal dry matter or crude protein contents in the diet. Journal Dairy Science, v.84, p.1728-1737, 2001.

CARNEIRO, A.M.; SANCHES., R.L.; RODRIGUES, N.M. et al. Consumo e digestibilidade "aparente" de silagens mistas de milho e soja anual. Arquivo da Escola Veterinária da UFMG, v.34, n.2, p.397-404, 1982.

CARNEIRO, A.M.; RODRIGUEZ, N.M. Influência da leguminosa na qualidade da silagem de milho. Arquivo da Escola Veterinária da UFMG, v.32, n.3, p.415-420, 1980.

CHIZZOTTI, F.H.M.; PEREIRA, O.G.; VALADARES FILHO, S.C. et al. Consumo, digestibilidade total e desempenho de novilhos nelore recebendo dietas contendo diferentes proporções de silagens de Brachiaria brizantha cv. Marandu e de sorgo. Revista Brasileira de Zootecnia, v.34, n.6, p.2427-2436, 2005 (supl.).

COFFEY, K.P.; GRANADE, G.V.; MOYER, J.L. Nutrient content of silages made from whole-plant soybeans. The Professional Animal Science, v.11, p.74-80, 1995.

CORRÊA, L.A.; POTT, E.B.; CORDEIRO, C.A. Integração de pastejo e uso de silagem de capim como estratégia na produção de bovinos de corte. In: SIMPÓSIO DE PRODUÇÃO DE GADO DE CORTE, 2., 2001, Viçosa, MG. Anais... Viçosa, MG: SIMCORTE: Universidade Federal de Viçosa, 2001. p.159-185.

COSTA, J.A.; MARCHEZAN, E. Características dos estádios de desenvolvimento da soja. Campinas: Fundação Cargill, 1982. 30p.

EICHELBERGER, L.; SIEWERDT, L.; SILVEIRA JR., P. Efeitos da inclusão de níveis crescentes de forragem de soja e uso de inoculante na qualidade da silagem de milho. Revista Brasileira de Zootecnia, v.26, n.5, p.867-874, 1997.

EVANGELISTA, A.R.; ABREU, J.G.; AMARAL, P.N.C. et al. Produção de silagem de capim-marandu (Brachiaria brizantha stapf cv. Marandu) com e sem emurchecimento. Ciência Agrotécnica, v.28, n.2, p.443-449, 2004.

EVANGELISTA, A.R.; REZENDE, P.M.; MACIEL, G.A. Uso da soja Glycine max (L.) Merril na forma de forragem. Lavras: Editora UFLA, 2003. 36p. (Boletim de Extensão).

EVANGELISTA, A.R.; GARCIA, R.; OBEID, J.A. et al. Consórcio milho-soja: Revista Brasileira de Zootecnia, v.20, n.6, p.578-584, 1991.

EVANGELISTA, A.R.; GARCIA, R.; GALVÃO, J.D. et al. Efeito da associação milho - soja no valor nutritivo da silagem. Revista Brasileira de Zootecnia, v.12, n.1, p.50-59, 1983.

FERRARI JR., E.; LAVEZZO, W. Qualidade da silagem de capimelefante (Pennisetum purpureum Schum.) emurchecido ou acrescido de farelo de mandioca. Revista Brasileira de Zootecnia, v.30, n.5, p.1424-1431, 2001.

FERREIRA, J.J. Estágio de maturação ideal para ensilagem do milho e do sorgo. In: CRUZ, J.C.; PEREIRA FILHO, I.A.; RODRIGUES, J.A.S.et al. (Eds.) Produção e utilização de silagem de milho e sorgo. Sete Lagoas: Embrapa Milho e Sorgo, 2001. p.405-428.

FEHR, W.R.; CAVINESS, C.E. Stage of soybean development. Iowa: Iowa State University, 1977. 12p. (Special Report 80).

HINTZ, R.W.; ALBRECHT, K.A.; OPLINGER, E.S. Yield and quality of soybean forage as affected by cultivar and management practices. Agronomy Journal, v.84, p.795-798, 1992.

HOFFMAN, P.; KRIEGL, T.; BORGES, R. [2004]. Handling, feeding and pricing soybean forage. Extension Responds: feed supplies. <http://www.uwex.edu/ces/ag/issues/winterfeed2004/ documents/Soybean_forage2004_.pdf> Acesso em: 18/1/2007.

JIMÉNEZ, C.; PINEDA, L.; LEÓN, B. et al. Planting maize in association with forage soybean for silage production. II. Indicators of silage quality. In: FEEDING SYSTEMS WITH FORAGE LEGUMES TO INTENSIFY DAIRY PRODUCTION IN LATIN AMERICA AND THE CARIBBEAN, 2004, Cali. Proceedings... Cali: International Center for Tropical Agriculture, 2004. (CD-ROM).

KOIVISTO, J.M.; DEVINE, T.E.; LANE, G.P.F. et al. Forage soybeans (Glycine $\max (\mathrm{L}$.) Merr.) in the United Kingdom: test of new cultivars. Agronomie, v.23, p.287-291, 2003.

KUNG JR., L.; TAYLOR, C.C.; LYNCH, M.P. et al. The effect of treating alfalfa with Lactobacillus buchneri 40788 on silage fermentation, aerobic stability, and nutritive value for lactating dairy cows. Journal of Dairy Science, v.86, p.336-343, 2003.

KUNG JR., L.; SHAVER, R. [2001]. Interpretation and use of silage fermentation analysis reports. University of Wisconsin Board of Regents, 2001. Focus on Forage, v.3, n.13, 2001. Disponível em: <http://www.uwex.edu/ces/crops/uwforage/ Fermentation.pdf $>$ Acesso em: 19/1/2007.

LEIBENSPERGER, R.Y.; PITT, R.E. A model of clostridial dominance in ensilage. Grass and Forage Science, v.42, p.297-317, 1987 .

LEMPP, B.; MORAIS, M.G.; SOUZA, L.C.F. Produção de milho em cultivo exclusivo ou consorciado com soja e qualidade de suas silagens. Arquivo Brasileiro de Medicina Veterinária e Zootecnia, v.52, n.3, p.243-249, 2000.

LOPES, J. Valor nutritivo das silagens. In: SIMPÓSIO SOBRE MANEJO DA PASTAGEM, 2., 1975, Piracicaba. Anais... 
Piracicaba: Escola Superior de Agricultura Luiz de Queiroz, 1975. p.187-218.

MARTIN, L.C.T.; GARCIA, R.; COELHO DA SILVA, J.F. Efeito da associação milho-soja (Glycine max) na qualidade da silagem. Revista Brasileira de Zootecnia, v. 12, n.3, p.562-575, 1983.

McDONALD, P.; HENDERSON, A.R.; HERON, S.J.E. The biochemistry of silage. 2.ed. Bucks: Chalcombe Publications, 1991. 340p

MUSTAFA, A.; McGILL P.S. [2005]. Effect of variety on chemical composition and ruminal nutrient degradability of forage soybean silage. Journal Animal Science, v.83, suppl.1 Disponível em: 〈http://www.fass.org/2005/abstracts/05abs383.pdf> Acesso em: 16/1/2007.

NATIONAL RESEARCH COUNCIL - NRC. Nutrient requirements of beef cattle. 7.ed. Washington, D.C.: National Academy Press, 2001. 381p.

OBEID, J.A.; GOMIDE, J.A.; CRUZ, M.E. et al. Silagem consorciada de milho (Zea mays) com leguminosas: produção e composição bromatológica. Revista Brasileira de Zootecnia, v.21, n.1, p.33-38, 1992.

OBEID, J.A.; GOMIDE, J.A.; CRUZ, M.E. Qualidade e valor nutritivo de silagem consorciada de milho (Zea mays) com soja anual (Glycine max. (L.) Merrill). Revista Brasileira de Zootecnia, v.21, n.1, p.39-44, 1992.

OBEID, J.A.; ZAGO, C.P.; GOMIDE, J.A. Silagem consorciada de milho (Zea mays) com leguminosas: produção e composição bromatológica. Revista Brasileira de Zootecnia, v.14, n.4, p.439-446, 1985.

RANGRAB, L.H.; MÜHLBACH, P.R.F.; BERTO, J.L. Silagem de alfafa colhida no início do florescimento e submetida ao emurchecimento e à ação de aditivos biológicos. Revista Brasileira de Zootecnia, v.29, n.2, p.349-356, 2000.

REZENDE, P.M.; SILVA, A.G.; CORTE, E. et al. Consórcio sorgosoja. VI. Estudo comparativo em função da rebrota de cultivares de sorgo e soja consorciados na entrelinha e em monocultivo no rendimento de forragem. Ciência Agrotécnica, v.24 (ed. especial), p.215-223, 2000.

RIBEIRO, A.C.; GUIMARÃES, P.T.G.; ALVAREZ, V.H. Recomendações para o uso de corretivos e fertilizantes em Minas Gerais: 5a aproximação. Viçosa, MG: Universidade Federal de Viçosa, 1999. p.99-110.

RODRIGUES, P.H.M.; BORGATTI, L.M.O.; GOMES, R.W. et al. Efeito da adição de níveis crescentes de polpa cítrica sobre a qualidade fermentativa e o valor nutritivo da silagem de capimelefante. Revista Brasileira de Zootecnia, v.34, n.4, p.1138$1145,2005$.

SILVA, B.C.; PEREIRA, O.G.; PEREIRA, D.H. et al. Consumo e digestibilidade aparente total dos nutrientes e ganho de peso de bovinos de corte alimentados com silagem de Brachiaria brizantha e concentrado em diferentes proporções. Revista Brasileira de Zootecnia, v.34, n.3, p.1060-1069, 2005.

SILVA, A.G.; REZENDE, P.M.; GRIS, C.F. et al. Consórcio sorgosoja. IX. Influência de sistemas de cortes na produção de forragens de sorgo e soja consorciados na linha e de sorgo em monocultivo. Ciência Agrotécnica, v.27, n.2, p.451-461, 2003.

SILVA, D.J.; QUEIROZ, A.C. Análise de alimentos (métodos químicos e biológicos). 3.ed. Viçosa: Editora UFV, 2002. 235p.

UNDERSANDER, D.; JARVIK, K.; ANDERSON, T. et al. [2006]. Soybean silage. Wisconsin crop manager. v.13, n.21. 2006. Disponível em: <http://beta.ipm.wisc.edu/WCMNews/tabid/53/ EntryID/186/Default.aspx> Acesso em: 11/1/2007.

Van SOEST, P.J. Nutritional ecology of the ruminant. 2.ed. Ithaca: Cornell University Press, 1994. 476p.

ZAR, J.H. Biostatistical analysis. Englewood Cliffs: PrenticeHall, 1999. 663p.

WEISS, W.P.; CONRAD, H.R.; PIERRE, R.S. A theoretically-based model for predicting total digestible nutrient values of forages and concentrates. Animal Feed Science and Technology, v.39, p.95-110, 1992. 